\title{
Educating Students with Disabilities Who Study at the University
}

\author{
Larisa V. Godovnikova ${ }^{1}$, Aleksandra S. Gerasimova ${ }^{1}$, Yana V. Galchun ${ }^{1} \&$ Victoria I. Orekhova ${ }^{1}$ \\ ${ }^{1}$ Federal State Autonomous Educational Institution of Higher Education, Belgorod National Research University, 85 \\ Pobedy St., Belgorod 308015, Russia \\ Correspondence: Larisa V. Godovnikova, Federal State Autonomous Educational Institution of Higher Education \\ Belgorod National Research University, 85 Pobedy St., Belgorod 308015, Russia. E-mail: godovnikova@bsu.edu.ru
}

Received: August 30, 2019

Accepted: December 11, 2019

Online Published: December 23, 2019

doi:10.5430/ijhe.v8n8p55

URL: https://doi.org/10.5430/ijhe.v8n8p55

\begin{abstract}
In this article the authors aim to analyze the ways of educating students with disabilities. Research activities at the university are the main type of educational and professional activities for students. Students with disabilities have difficulties in organizing research activities. Students have difficulties in self-regulation, their goals in research activities related to internal well-being. The communicative orientation is a leading emotional focus in research activities, and the motivation for research activities reduced. We have developed and implemented a program of training, which allowed us to develop the components of self-organization of research activities for students with disabilities. The development of such personal characteristics as self-regulation of behavior and emotional orientation positively influence the motivation of research activities among students with disabilities.
\end{abstract}

Keywords: educating, teaching methods, students with disabilities

\section{Introduction}

Nowadays, the need for highly qualified specialists employed in knowledge-intensive industries is growing, so higher education becomes the key to successful employment. For people with disabilities, high education is also an effective mechanism for raising social status, ensuring economic independence and integrating into society.

In the universities of the Russian Federation, the issue of creating special conditions for students with disabilities is relatively new. The focus is on to create regulatory, organizational, managerial, informational and methodological support of the process for training students with disabilities. Most people, who concerned about helping students with disabilities, believe that the main task in realizing their right to accessible education is to increase the level of physical accessibility to the educational process and objects of social, transport and architectural infrastructures. However, as practice showed, physical accessibility to various facilities of the university infrastructure is not enough for students with disabilities. They need special assistance and support during the educational process.

The organization of psychological and pedagogical support of educational and professional activities in the university will contribute to the optimal socialization of students with disabilities.

Students with disabilities are an extremely diverse group of students, each with their individual and special educational needs, their own resources, and, accordingly, the difficulties that they face in the process of vocational education are different. During organizing psychological and pedagogical support, we pay attention to all difficulties that are caused by the general characteristics of students with disabilities and take into account the individual properties and resources of each student.

The success of university studies depends on the psychological readiness of students with disabilities to educational and professional activities. Research activity is the main type of educational and professional activities at the university. Students with disabilities during their studying at the university have great difficulties in organizing research activities. Research motivation has particularly low rates for students with disabilities.

\section{Theoretical Background of the Study}

In the structure of personality, motivation holds a special place and it is the main concept used to explain the ways of behavior and human activity. The motive is understood as a complex systemic psychological education, an incentive to the activity recognized by the subject of activity (Ilyin, 2000). The motive and motivation are internal, and all other motivators and influences are external factors. Motivation can be influenced by circumstances, factors, conditions. Ilyin (2000) notes that motivation is a dynamic process of motive formation (the basis of an act). 
Any activity is motivated when it is aimed at achieving the specific goal of a specific motive. It depends on motivation, how and in what direction various functional abilities of a person, his interests and aspirations will be used. Motivation explains the choice between various possible actions, the intensity and perseverance of the subject in the implementation of the chosen action and the achievement of its results. Zubareva \& Motovits (2014) investigated the international experience of staff motivation and confirmed the role of motivation in business performance.

The motivation of research as a special kind of motivation is interpreted by the authors in different ways. Mazaletskaya (2011) considers the motivation of research activities as a system of factors, including all kinds of motives. Markova (2016) understands the motivation of cognitive activity as a system of internal and external factors that encourage activity. Gorshkova (2013) considers the motivation of research activities as the focus of the individual on certain aspects of the activity. Dolgova (2004) considers the motivation of the research activities of students as a specific set of human qualities. Medvedeva (2015) The scientist understands motivation as a creative activity, the desire to obtain personal desire.

Santos, Antunes, Bernardi (2008) understand motivation as a process that includes the inner and outer motives of each person, motives that were built in social interactions from early childhood and which ultimately carry out intrapersonal relations.

Santos, Stobäus, Mosquera (2007) say that motivation is characterized by an internal desire to achieve a goal, so it is an analysis of the possibilities of achieving a certain goal and performing certain actions planned for this purpose.

Carmen, Sá, Santos (2016) identify the following reasons for reducing the motivation of research activities: low wages, high working hours, low prestige.

Rabelo (2010) identifies aspects that are integral to learning: taste preferences for activities and attempts to reconcile economic, social and family aspects. To external factors can be attributed to the inability to engage in other activities. In this case, continuing education in the higher stages of the institution is a choice of hopelessness. He recognized that most students choose this path of study because they expect satisfaction from internal factors in their future work.

Opstrup \& Kaarsted (2017) in order to increase the intrinsic motivation, researchers propose a new financing system. They guess that increasing wealth will allow researchers to feel more comfortable, to feel the importance of research from society, to feel the prestige of their activities.

Nickenig, Oliveira, Gil, Calvo, Stival, Yen, Haglund \& Staton (2018) studied on the motivation and habits of high-performing researchers from around the world. This study allowed to identify the main markers of high productivity of research activities:

"The ability to represent your thoughts correctly and easily";

"Previous research experience";

"Leadership skills";

"Adaptation to various conditions";

"Ability to work in a short time";

"Use of innovative technologies in their activities".

Mehmet (2016) described interesting facts about the motives of research activities of young researchers. The main motives for young researchers are: contribution to human life, scientific curiosity, career, contribution to science and prestige. Also, young scientists believed that money is the lowest motivating element for scientific research. These four motivational elements can be considered as intrinsic motivation.

The study was a striking result that scientists who did not consider themselves competent in the use of new technologies had a more extrinsic motivation. The study showed that the research culture of scientists who do not have competence in the use of new technologies may not be developed. Self-relation as an effective scientist will fall against the background of scientists who use new technologies and develop their research activities more effectively (Mehmet, 2016).

Yi, Liqing, Jia, Changkun (2015) showed the mechanism of influence of external motivation on internal motivation through the styles of interaction with the supervisor. In the course of this study, it was revealed that the democratic leadership style favorably influences the development of students' internal motivation, extending rights and opportunities, the student develops his skills in research activities and becomes more effective. The opposite effect was 
the authoritarian leadership style, which negatively influenced the students' internal motivation and limited their possibilities.

Materova (2012) believes that the general characteristics of the motivational sphere may have a different character. However, for research activities it is necessary that the motivational sphere be dominant in nature, focused on the creative activity of the individual, suggesting a consistently high level of claims.

Markova (2016) considers motivation as a vector of activity, therefore, the teacher needs to know what motivates the learner to be active (Zhaleh et al, 2018).

Mazaletskaya (2011) believes that the motivation of research activities is developing in stages, the transition to the next stage depends on the change of the leading factor. The author identifies three factors:

1. The primary motivation of research activities - the leading factor - communication.

2. The motivation of research activities in vocational training is the leading factor - material wealth.

3. The motivation of research activities in professional adaptation is the leading factor - the need for structuring work, feedback and information about one's own work.

Motivation research has a certain structure (Mazaletskaya, 2011):

- need to acquire information;

- needs for creativity;

- need for independence, individuality;

- need to improve the professional level.

Gerasimova (2006) believes that the motivation of research activities is based on the ratio of focus and measure of effectiveness. Based on it, she identifies the following levels of motivation for research activities of a postgraduate:

1. A high level is characterized by a wide acting orientation of a postgraduate not only on the result of research work, the material and social benefits that he gives, but also on self-development in the process of activity.

2. The average level characterized by a narrow current focus of a postgraduate only on the result of research activities and the material and social benefits that he provides.

3. The level below the average is characterized by a broad focus on the result and on self-development, which does not affect the behavior and remains only known.

4. The low level characterized by a narrow focus on the result of research work, material and social benefits, which does not affect the behavior of postgraduates.

5. The lack of motivation for research activities characterized by an unconscious and situational orientation of the individual, when engaged in research work.

The analysis of scientific research presented earlier allowed us to draw a number of conclusions that are fundamental for our work. We consider the motivation of research activities of students as the focus of students on certain aspects of research activities related to the internal attitude to the activity. The development of research motivation depends on external and internal conditions. Internal conditions include personal characteristics of students. Such features were the emotional focus in research activities and the style of self-regulation of students. We have assumed that by changing the emotional orientation of students in research activities and the style of their self-regulation, it is possible to achieve positive changes in the motivation of research activities.

\section{Methodology}

We have developed and implemented a training program aimed in developing the components of the self-organization of research activities. The program was substantiated by the results of a theoretical and empirical study of personality determinants of the motivation of research activities of students with disabilities and understanding of the special role of the style of self-regulation of personal behavior in the formation and development of such motivation.

As an experimental group in our research we've chosen the students with disabilities of the Belgorod State National Research University. Our previous research showed that students with disabilities experienced serious difficulties with the organization of research activities (Godovnikova, Gerasimova, Galchun, Shitikova, 2019).

The study was attended by 9 students, among them 6 graduate students ( $67 \%$ under experiment), for whom the issue of organizing research activities is particularly relevant due to their need to prepare the final qualifying work. 
The diagnostic program included the following techniques:

1) the questionnaire "Style of self-regulation of behavior with a scale of reliability" (Morosanova and Bondarenko, 2015);

2) the questionnaire "Personal goals of students engaged in research activities" (author: Gerasimova);

3) test questionnaire "Emotional orientation" (Test questionnaire "Emotional orientation"; Dodonov, 2009);

4) the value-normative methodology for studying the motivational readiness of students for research activities (author: Gerasimova).

\section{Results and Discussion}

We analyzed the results of diagnostics of motivational readiness for research activities of students with disabilities before and after conducting training. The results showed the effectiveness of the special work on the development of personal determinants of motivational readiness for research activities.

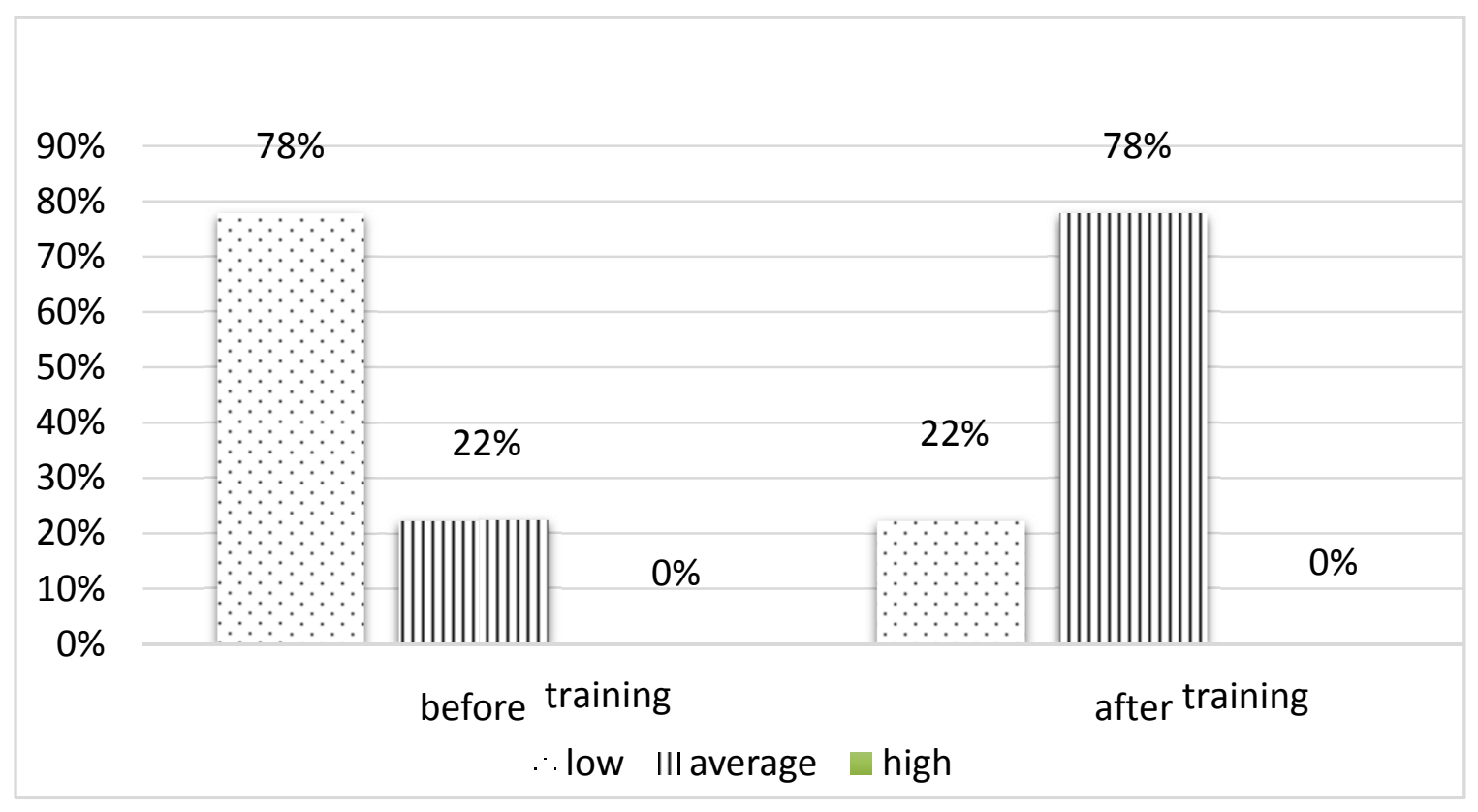

Figure 1. Changes in self-regulation of students with disabilities

Since the training was aimed at the development of students' self-regulation in research activities, the changes in self-regulation indicators for us were the most informative. The general dynamics of the development of students' self-regulation is presented in Figure 1. 56\% of students increased the level of self-regulation in comparison to the results before the training. After the training, $78 \%$ of students showed the average level of self-regulation. Students have shown that they are, as we see, independent, they can flexibly and adequately respond to a change in conditions, the nomination and achievement of a goal to a large extent consciously. With high motivation, achievements are able to form such a style of self-regulation, which will allow to compensate for the influence of personal, characterological features that impede the achievement of a goal. 


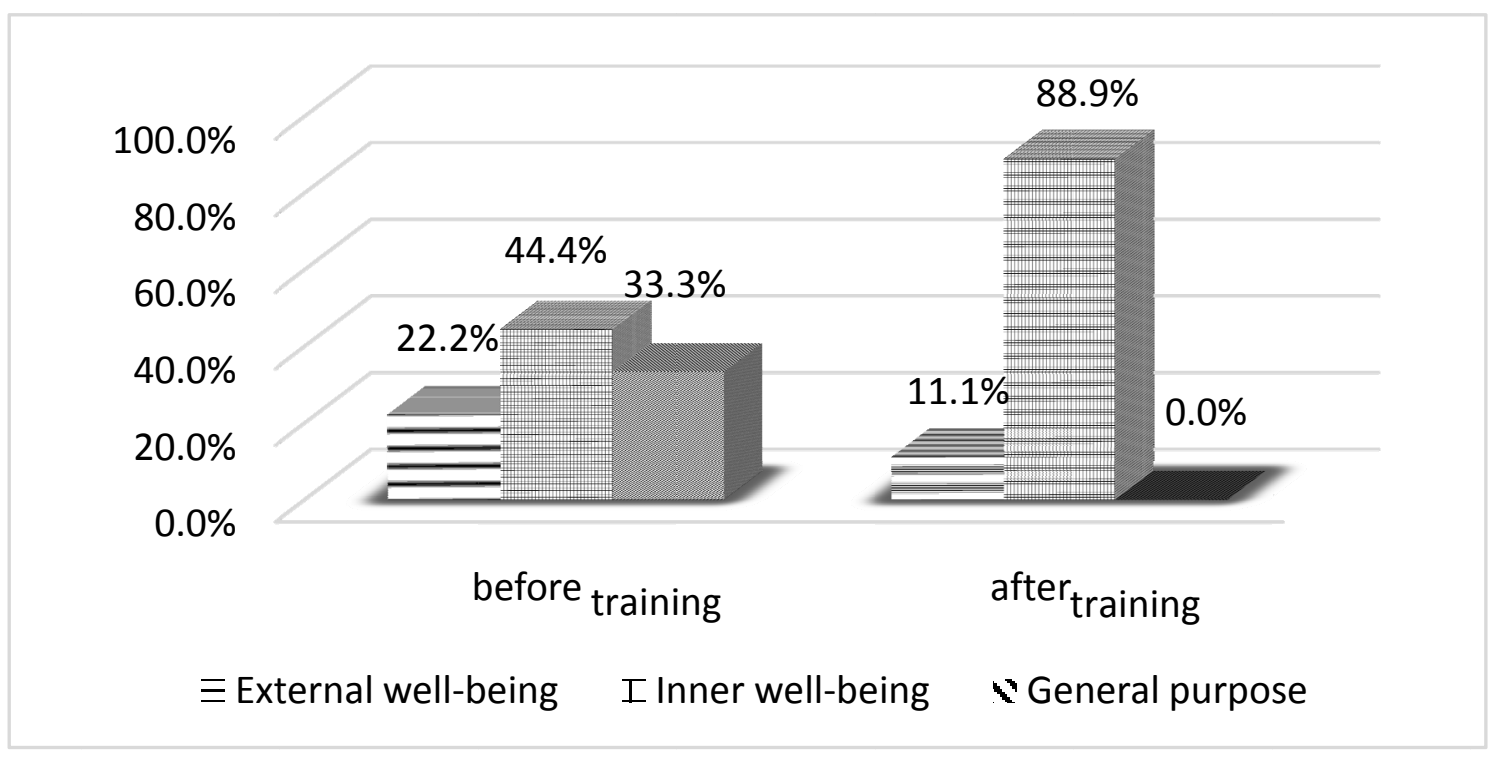

Figure 2. Changes in objectives in research activities of students with disabilities

There were changes in the leading objectives in research activities of students with disabilities (Figure 2). The number of students with prevailing goals of external well-being has decreased to $11 \%$, the goals of general purpose are not presented at all, and the number of students with goals of internal well-being has increased to $45 \%$. After the training, $89 \%$ of students with disabilities were dominated by the goals of internal well-being in research activities. There has been a shift of priorities from the social purpose of the profession to knowledge, self-knowledge, self-development, self-realization in the process of research activities.

The study of the emotional focus in research activities before and after the training once again confirmed the importance of communicative emotions. Communication emotions increased to $22 \%$. Students with disabilities, carrying out research activities, seek to satisfy the need for communication, the need to have a friend, a sympathetic interlocutor. Nevertheless, they are interested in self-assertion, fame, as well as emotions associated with the process of research activities.

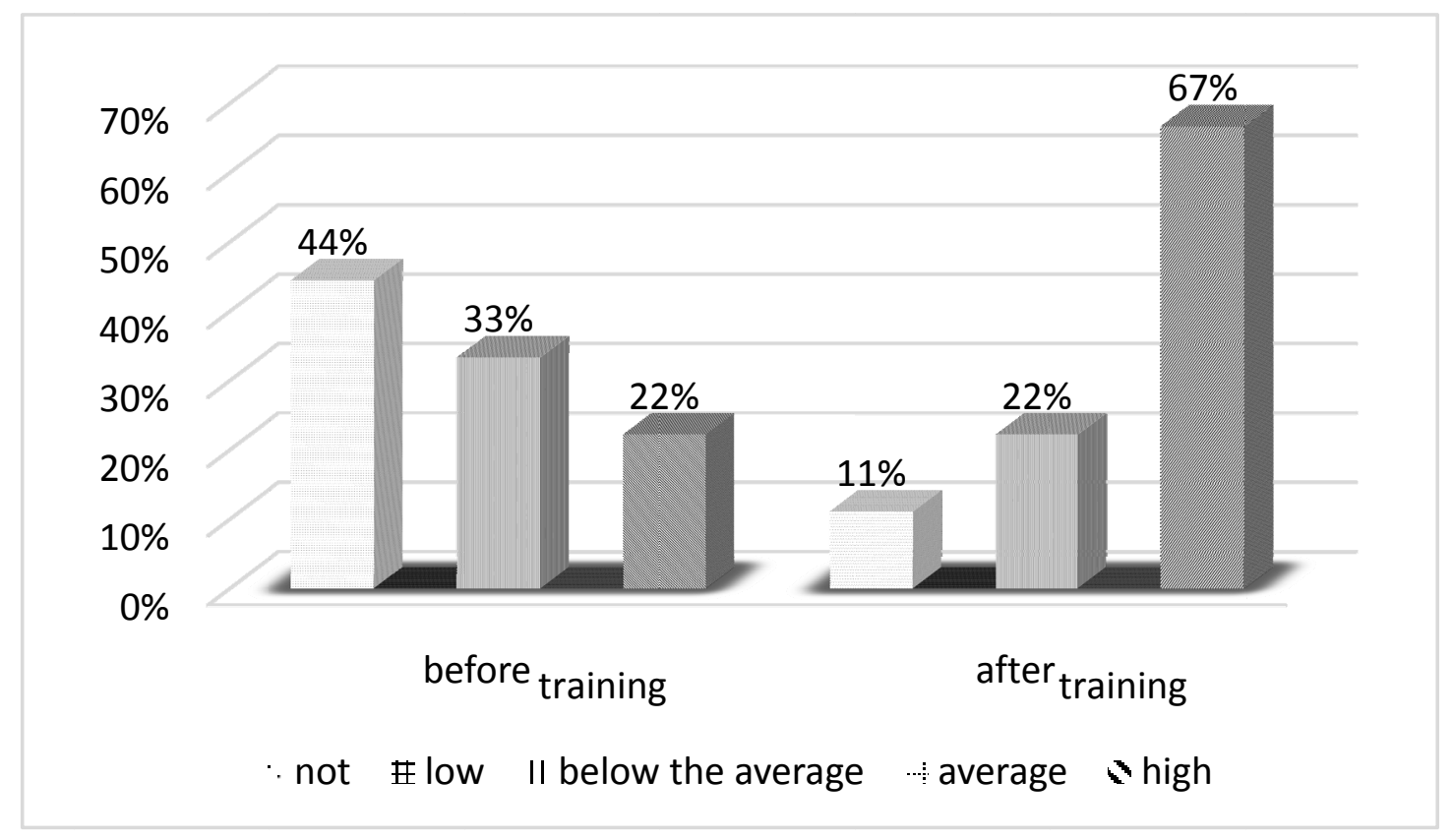

Figure 3. Dynamics of motivation for research activities of students with disabilities 
The dynamics of motivation for research activities of students with disabilities are shown in Figure 3 . The level of motivation for research activities of students with disabilities increased to $44 \%$. This confirmed our assumption that the development of self-regulation in research activities will increase the degree of motivation for this activity. As a result of the work done, $67 \%$ of students, besides to want getting a diploma, professional status and respect of others, developed a desire for inner self-development. Students are characterized by the desire to learn new things, find answers to personal questions; their internal position is consistent with the actions.

\section{Conclusion}

Our research showed that the style of self-regulation of individual behavior affects the formation and development of research motivation among students with disabilities. The study determined the content of the work of the psychological service to ensure the socio-psychological adaptation of students with disabilities to the environment of the university.

We developed and tested a program for teaching students with disabilities effective and rational methods of research and development activities for self-realization and self-affirmation of each individual in this type activity.

Psychological programs for overcoming internal barriers and updating developmental resources and self-development of students with disabilities were developed and tested on the basis of the Psychological Service of the Belgorod State National Research University.

Issues that need further development:

Developing mechanisms for interaction with employers to help students with disabilities to build a successful career in the field of science, technology and innovation.

\section{References}

Carmen, S. da S. \& Sá, W. L. P., Santos (2016). Quím. Nova. Sao Paulo, 39(1), from http://dx.doi.org/10.5935/0100-4042.20150155.

Dolgova, N.V. (2004). Motivation of research activities of students. Periodical of Young Scientists, 1, 45-47. (In Russian).

Efimova, I.N. (2014). Analysis of the motivation of the professional choice of students for the purpose of training with particular knowledge of the history and culture of Islam as a tool for assessing the quality of knowledge. Periodical of UNN, 1(1). (In Russian).

Gerasimova, A.S. (2006). The motivation of learning in the context of the activity approach: a tutorial. BelSU Publishing House, 140. (In Russian).

Godovnikova, L. V., Gerasimova, A. S., Galchun, Y. V. \& Shitikova, E. V. (2019). The competency levels of disabled students who study in university. Cypriot Journal of Educational Sciences, 14(1), 009-110.

Gorshkova, O. O. (2013). Components of the research competence of the future engineer. Proceedings of the scientific-practical conference "Problems of engineering education in a technical college in the context of the modernization of higher professional education.", 68-71. (In Russian).

Ilyin, E.P. (2000). Motivation and motives, 215. (In Russian).

Markova, A.K. (2016). Formation of teaching motivation: Book for teacher, 192. (In Russian).

Materova, A. V. (2012). Motivation of the research activity of students. Periodical of RUDN. Series: Psychology and Pedagogy. $1 . \quad$ from https://cyberleninka.ru/article/n/motivatsiya-nauchno-issledovatelskoy-deyatelnosti-studentov (access date: 04/20/2019). (In Russian).

Mazaletskaya, A.L. (2011). Dynamics of motivation of research activities at the stages of professionalization. thesis: 19.00.03, 26. (In Russian).

Mazaletskaya, A.L. (2011). Motivational features of research activities of university students. Publishing house of SPGU, 309-311. (In Russian).

Medvedeva, Yu.S. (2015). Motivation of a scientist at the pre-university and university stages of professionalization: similarities and differences. Proceedings of the Intern. youth scientific Forum "LOMONOSOV-2015", 67-76. (In Russian). 
Mehmet, F. (2016). Examination of Scientific Research Motivation and Methodological Paradigms of ICT Oriented Young. Education Researchers, 41(187), 221-237.

Morosanova, V.I. \& Bondarenko, I.N. (2015). Diagnosis of human self-regulation. University psychological education, 304. (In Russian).

Nickenig, V. J., Oliveira, A., Gil, N., Calvo, P., Stival, N., Yen, T., Haglund, M. \& Staton, C. (2018). To be highly productive in the biomedical sciences: a qualitative study of motivation and habits of high-performance researchers. Management and Society, 13(34), from https://doi.org/10.21171/ges.v13i34.2472.

Opstrup, N. \& Kaarsted, T. (2017). From a "taste of science" to a "taste for publications"? A qualitative study of how performance-based university research funding systems impact researchers' intrinsic motivation, 9, 524-539.

Rabelo, A. O. (2010). Lusófona Magazine of Education. 15, 163.

Santos, B. S., Antunes, D. D. \& Bernardi, J. (2008). Education, 31, 46.

Santos, B. S., Stobäus, C. D. \& Mosquera, J. J. M. (2007). Education special, 297.

Test questionnaire "Emotional orientation" (B.I. Dodonov) // Diagnostics of emotional and moral development / Editor and compiler I.B. Dermanova. - SPb., 2002, 132-134. (In Russian).

Yi, M., Liqing, Z., Jia, H. \& Changkun, L. (2015). Supervisors' leadership and health science researchers' intrinsic motivation: The mediate role of psychological empowerment. Nankai Business Review International, 6(1), 68-81, from https://doi.org/10.1108/NBRI-01-2014-0007.

Zhaleh, K., Ghonsooly, B., \& Pishghadam, R. (2018). Effects of Conceptions of Intelligence and Ambiguity Tolerance on Teacher Burnout: A Case of Iranian EFL Teachers. Research in Applied Linguistics, 9(2), 118-140.

Zubareva, Ye. A. \& Motovits, T. G. (2014). International Experience of Personnel Motivation in the Conditions of Modern Economy. Scientific notes. PNU, 4, 54-68. (In Russian). 